$\mathrm{MFN}=007122$

01 SID/SCD

025710

03 INPE-5710-PRE/1872

04 CEA

$05 \mathrm{~S}$

06 as

10 Abdu, Mangalathayil Ali

10 Batista, Inez Staciarini

10 Sobral, Jose Humberto Andrade

12 A new aspect of magnetic declination control of equatorial spread $\mathrm{F}$ and $\mathrm{F}$ region dynamo

14 14897-14904

30 Journal of Geophysical Research

3197

32 A10

$40 \mathrm{En}$

$41 \mathrm{En}$

$42<\mathrm{E}>$

58 DAE

$61<\mathrm{PI}>$

64 Oct. $<1992>$

68 PRE

76 AERONOMIA

83 Range spread $F$ (RSF) data for a 12 -year period (1978-1990) over the Brazilian low-latitude station, Cachoeira Paulista, are analyzed to determine the fine structure of the seasonal pattern of the irregularity occurrence, which appears consistent throughout an entire solar cycle. The RSF occurrence for one of these years is compared also with that over the equatorial station, Fortaleza, to show that the seasonal pattern discussed here corresponds to that of plasma bubble irregularity developments. A striking result that has come out of the present analysis concerns two secondary minima, during the epoch of broad annual maximum, in the RSF that occur in association with the two nodal points at the magnetically conjugate $\mathrm{E}$ layer sunset local times, that is, at the perfect alignment of the sunset terminator with the magnetic meridian of the station. The occurrence of these minima, seen in individual solar minimum and solar maximum years (as also in the overall mean behavior), is interpreted on the basis of a simplified $F$ region dynamo development model that considers also asymmetric conjugate $\mathrm{E}$ layer decay conditions. Competing roles of a prereversal zonal electric field enhancement and of its height gradient seem to determine the occurrences of these secondary $90 \mathrm{~b}$ minima in R.SF.

91 FDB -19960313

92 FDB-MLR 


\title{
A New Aspect of Magnetic Declination Control of Equatorial Spread F and F Region Dynamo
}

\author{
M. A. Abdu, I. S. Batista, and J. H. A. Sobral
}

Instituto Nacional de Pesquisas Espaciais, Säo José dos Campos, Brazil

\begin{abstract}
Range spread F (RSF) data for a 12-year period (1978-1990) over the Brazilian lowlatitude station, Cachoeira Paulista, are analyzed to determine the fine structure of the seasonal pattern of the irregularity occurrence, which appears consistent throughout an entire solar cycle. The RSF occurrence for one of these years is compared also with that over the equatorial station, Fortaleza, to show that the seasonal pattern discussed here corresponds to that of plasma bubble irregularity developments. A striking result that has come out of the present analysis concerns two secondary minima, during the epoch of broad annual maximum, in the RSF that occur in association with the two nodal points at the magnetically conjugate $E$ layer sunset local times, that is, at the perfect alignment of the sunset terminator with the magnetic meridian of the station. The occurrence of these minima, seen in individual solar minimum and solar maximum years (as also in the overall mean behavior), is in terpreted on the basis of a simplified F region dynamo development model that considers also asymmetric conjugate $E$ layer decay conditjons. Competing roles of a prereversal zonal electric field enhancement and of its height gradient seem to determine the occurrences of these secondary minima in RSF.
\end{abstract}

\section{INTRODUCTION}

Equatorial spread F (ESF) irregularity events, often associated with plasma-depleted magnetic flux tubes, namely, plasma bubbles, that characterize the unstable state of the nighttime equatorial ionosphere have been the subject of somewhat extensive investigations using a variety of radio, optical, and in situ diagnostic techniques. Some examples of the studies conducted using ionosondes, VHF radars, scintillation receivers, photometers/imagers, and in situ rocket and satellite measurements are those of $A b d u$ et al. [1981a, b, 1983a, 1991], Basu and Basu [1981], Chandra and Rastogi [1972], DasGupta et al [1982], Farley et al [1970], Hanson and Sanatani [1973], Hanson and Bamgboye [1984], Huang et al. [1987], Kelley et al. [1976], McClure et al. [1977], Mendillo and Baumgardner [1982], Rastogi [1985], Sobral et al. [1980], Sobral and Abdu [1990], Tsunoda [1981], Tsunoda et al. [1982], Weber et al. [1980], Woodman and La Hoz [1976], and Yeh et al. [1981]. Theoretical and simulation studies to explain the different observational results (see, for example, Haerendel [1973], Ossakow et al. [1979], and Zalesak et al. [1982]) do seem to agree on irregularity generation based on the gravitational Rayleigh-Taylor (R-T) instability (or generalized gradient drift instability) mechanism. An important aspect of the ESF that is of prime interest at present concerns the ambient ionospheric electrodynamics leading to the plasma instability processes that produce the irregularities. One of the well-known prerequisites for the onset of the ESF is the rapid evening uplift of the $\mathrm{F}$ layer $[A b d u$ et al., 1983b; Farley et al, 1970] under the action of the $F$ region dynamo, which produces the prereversal enhancement in the eastward electric field [Woodman, 1970; Fejer et

Copyright 1992 by the American Geophysical Union.

Paper number 92JA00826.

0148-0227/92/92JA-00826\$05.00 al., 1979]. According to the F layer dynamo theory by Rishbeth [1971] and the numerical simulation studies based on the same by Heelis et al. [1974], a zonal thermospheric wind, blowing eastward from the highly conducting dayside ionosphere to the nightside of low conductivity, that is, in the presence of a longitude gradient (westward) in the Pedersen conductivity, could produce the enhanced eastward prereversal electric field (namely, the vertical uplift of the layer). Thus the intensity of the wind and the magnitude of the Pedersen conductivity longitudinal gradient determine the evening F region vertical drift enhancement (see also Batista et al. [1986]). The magnitude of the conductivity longitudinal gradient, in turn, is determined by the degree of simultaneity of sunset at magnetically conjugate $\mathrm{E}$ layers that are coupled to the equatorial $\mathrm{F}$ region. Simultaneous sunset at the conjugate $\mathrm{E}$ layers that occurs under perfect alignment of the sunset terminator with the magnetic meridian, for example, will produce the largest value of the conductivity gradient compared to its value for different degrees of deviation from a perfect alignment. On the other hand, the equatorial magnetic declination has significant variation with longitude, its largest magnitude of $\sim 22^{\circ} \mathrm{W}$ occurring in the Brazilian sector. In this way the magnetic declination angle controls the longitudinal and seasonal dependencies of the $F$ region dynamo effect on the prereversal vertical drift enhancement and the ESF, as was first demonstrated by Abdu et al. [1981b]. From analysis of global VHF scintillation data sets, Tsunoda [1985] showed that seasonal variation in the scintillation occurrence and its longitude dependence could indeed be explained to the first order by the longitude dependent magnetic declination angle. The paper by Batista et al. [1986], on numerical simulation of the $\mathrm{E}$ and $\mathrm{F}$ layer electrical coupling (see also Heelis et al. [1974]), discussed the control of the $F$ region vertical drift by magnetic declination angle as well as by different zonal wind intensities. From the 
previous studies mentioned above, the general finding is that the seasonal maximum in spread F (and scintillation) irregularities at a given longitude occurs around the season when the sunset terminator nearly aligns with the magnetic meridian, corresponding to almost simultaneous sunset at conjugate $\mathrm{E}$ layers. Thus the spread $\mathbf{F}$ maximum season in Brazil (with declination angle $\sim 22^{\circ} \mathrm{W}$ at Fortaleza) is centered around the solstitial month December [Abdu et al, 1981b], whereas at Huancayo/Jicamarca, in Peru (declination angle being $4^{\circ} \mathrm{E}$ ), located only $30^{\circ}$ westward in the South American continent, two maxima occur, centered around the equinoctial months of September and March [e.g., Ras$\operatorname{tog} i, 1980]$.

The maxima in the vertical drift of the layer around the nodal points in the conjugate $\mathrm{E}$ layer sunset local time curves (such as those given in Figure 4 of Batista et al. [1986]) may not, however, signify irregularity maxima at the same nodal point conditions, since other factors besides the vertical drift velocity (or rather a height independent drift) could control the irregularity generation and growth. In order to verify this point we have analyzed here 12 years of range spread $F$ (RSF) data over the Brazilian low-latitude station Cachoeira Paulista ( $-28^{\circ}$ dip angle). The data over the low-latitude station are chosen for this verification in preference to the data over an equatorial station (such as Fortaleza) because the RSF over the former station represents the irregularities arising from the plasma bubble development and vertical growth over the equator. Though this last point has been discussed in some of our previous papers [e.g., $A b d u$ et al., 1983a], a further clarification of the same is attempted here, showing complementary evidence, by comparing concurrent RSF occurrences at the equatorial and low-latitude stations. The overall emphasis of the present analysis is on the detailed and finer features of the irregularity distribution pattern during the spread $F$ occurrence season, from October to March, which repeat themselves for a complete solar cycle.

\section{RESULTS}

The monthly mean range type spread F (RSF) distribution as a function of local time (at 15-min resolution) for a complete year, 1980-1981, a solar maximum epoch, is presented in Figure 1 as contour lines of percentage occurrence for the equatorial station Fortaleza ( $-5^{\circ} \mathrm{dip}$ ). The period from August to April has a high rate of RSF occurrences, the percentage for the evening to premidnight hours lying in the range of 90 100. The decrease in RSF from April to May is usually very abrupt. But the large difference between the April 1981 and the May 1980 occurrence percentages in Figure 1 seems to have superimposed on it a component of year-to-year variability as well. The RSF onset time varies mostly from 18 to $19 \mathrm{LT}$. The two arrows on the right side of the figure point to a perceptible reduction in occurrence rate around February and November. This feature will constitute the main focus of attention in this paper. Results similar to those for Fortaleza are presented in Figure 2 for Cachoeira Paulista, a lowlatitude station $\left(-28^{\circ} \mathrm{dip}\right)$, for the same 1-year period as that of Figure 1. Comparison with the results for
FORTALEZA (1980- $\$ 981)$

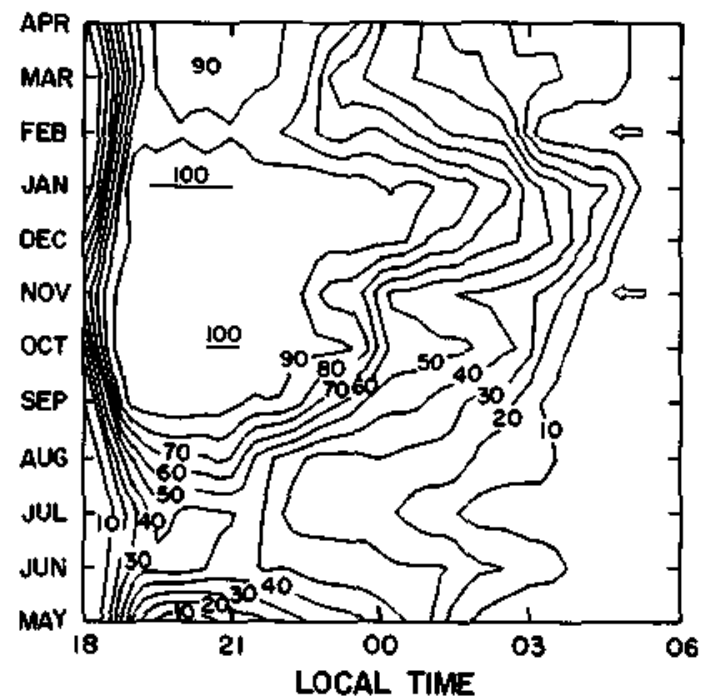

Fig. 1. Monthly mean RSF occurrence percentages versus local time distribution contours for the years 1980-1981 over Fortaleza.

Fortaleza brings out the following points: (1) the RSF onset times over Cachoeira Paulista occur later than 1900 LT with more than $50 \%$ of the cases always occurring after $2000 \mathrm{LT}$, which represents a significant delay with respect to such results for Fortaleza (see also $A b d u$ et al. [1983a], and (2) the RSF occurrence percentages for Cachoeira Paulista are significantly reduced compared to those for Fortaleza, and the 90\% occurrence now becomes confined to December.

The delay and reduced occurrence of spread $\mathrm{F}$ at $\mathrm{Ca}$ choeira Paulista with respect to that over Fortaleza are consistent with the results presented by Rastogi [1983] for the Pacific zone. Both aspects 1 and 2 are consistent with the interpretation that the vertical growth of flux tube aligned plasma bubbles over the equator is responsible (through the associated latitudinal expansion) for the RSF observed over an off-equatorial (low latitude) station. They also show that a significant percentage of the total RSF events over the equator remain and decay as bottomside events. Also presented in Figure 2 are the vertical drift velocity prereversal enhancement, $V_{z p}$, deduced from Fortaleza ionograms (which is relevant for the RSF occurrences over Cachoeira Paulista), and sunset local times [from Batista et al., 1986] at the $E$ layers ( $T_{S C E 1}$ and $T_{S C E 2}$ ) that are conjugate for a field line that has its apex in the $F$ region over Fortaleza where the geomagnetic declination angle is $22^{\circ}$ westward. There is a rather clear tendency for large $V_{z p}$ values and higher plasma bubble occurrences during months corresponding to smaller values of conjugate E layer sunset time differences. In this figure also, two arrows point to a small reduction in the plasma bubble occurrence percentages, which coincide almost exactly with the months when a similar reduction was present in Figure 1 as well.

The variations for a complete solar cycle, 1978-1990, in RSF onset times for Cachoeira Paulista are shown in Figure 3 for each of the 6 months of large occurrence rates, that is, from October to March. In this figure the solid circles represent the RSF onset times over Forta- 


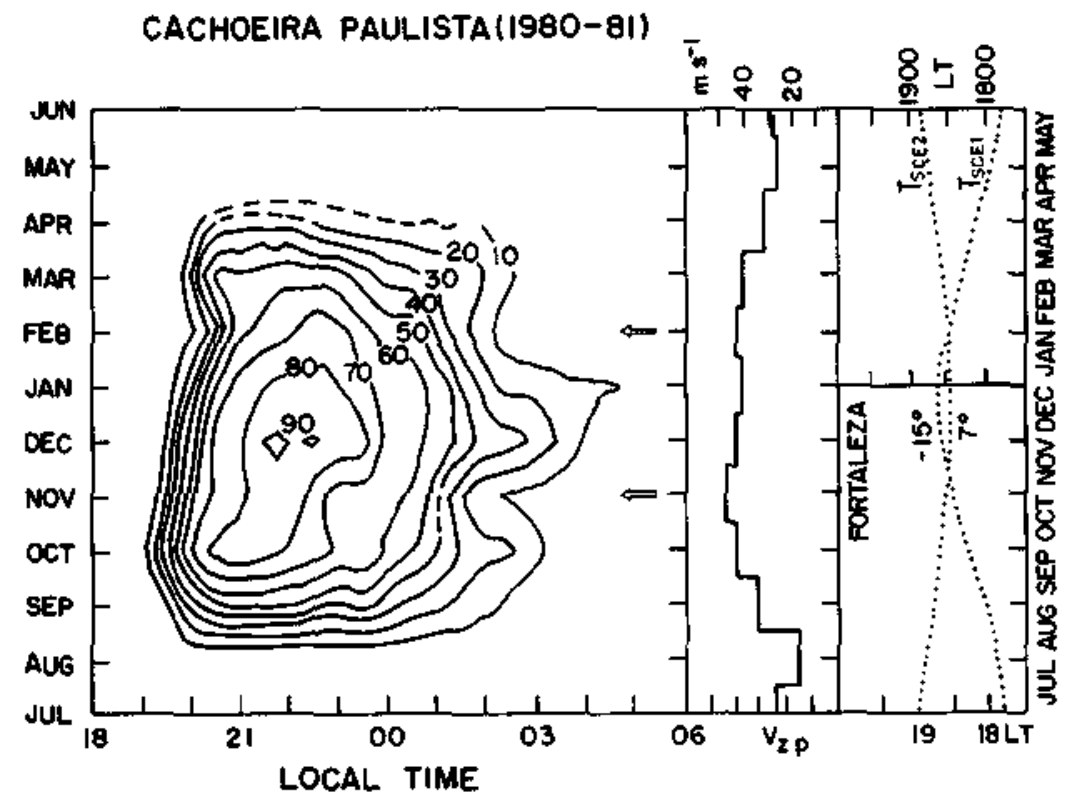

Fig. 2. (Left) RSF distribution contours similar to those of Figure 1 plotted for Cachoeira Paulista. (Right) The prereversal $F$ region vertical drift velocity in meters per second and the sunset local times at magnetically conjugate $\mathrm{E}$ layers (at $-15^{\circ} \mathrm{dip}$ and $7^{\circ}$ dip values) plotted for the entire year.

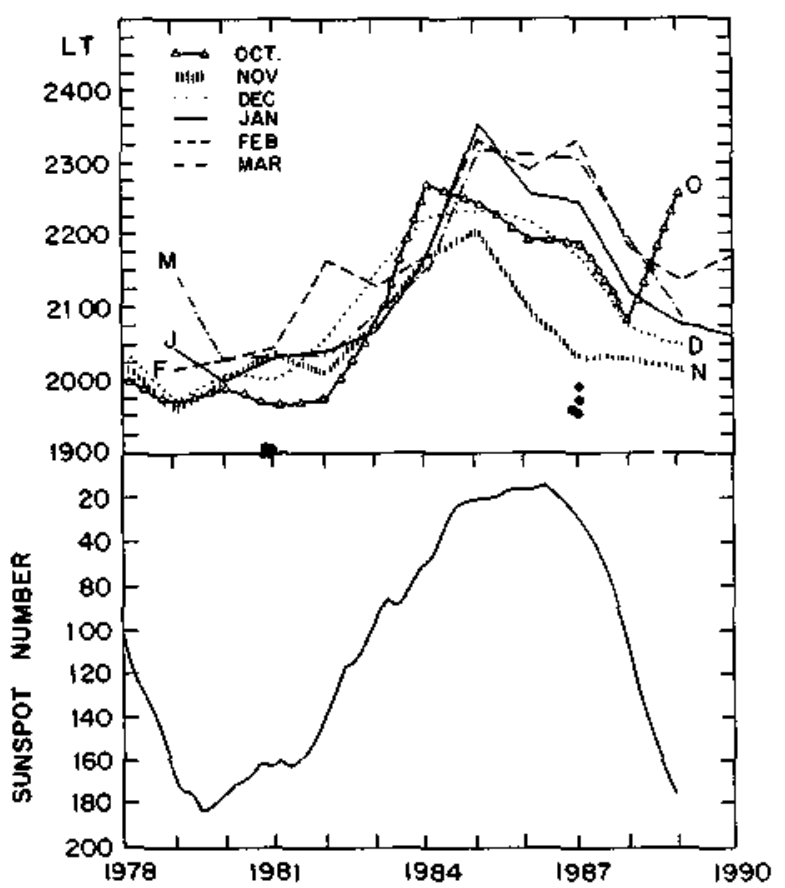

Fig. 3. (Top) RSF onset local time monthly mean values at Cachoeira Paulista plotted separately for 6 months through the years 1978-1990. The solid circles are those values for Fortaleza for a few months during 1981 and 1987. (Bottom) Sunspot number variations during the same period.

leza for a few months in 1981 (solar maximum) and for 1987 (solar minimum). The average delay in RSF onset over Cachoeira Paulista with respect to that over Fortaleza, which is of the order of 1 hour during solar maximum, increases to the order of 3 hours during solar minimum. This is consistent with a reduction in the average plasma bubble rise velocity over the equator from $\sim 180 \mathrm{~m} \mathrm{~s}^{-1}$ to $\sim 60 \mathrm{~m} \mathrm{~s}^{-1}$ during the same period and thus supports the contention that the RSF observed over the low-Jatitude station Cachoeira Paulista does indeed represent cases of plasma bubble events.

In order to check if any consistent trend is present in the seasonal pattern of the plasma bubble/spread $\mathbf{F}$ occurrences for an entire solar cycle, we analyzed the RSF data over Cachoeira Paulista for the years 1978 through 1990. The RSF data at 15-min resolution were used to obtain the percentage occurrence in the 12-year period at each sounding local time of each day of the year for the interval from October to March. The results of this statistical analysis are presented as contour plots of percen tage occurrences in local time versus day of the year format in Figure 4a. The grid points have a separation of 1 day along the abscissa and $15 \mathrm{~min}$ along the ordinate. Figure 4d shows conjugate $\mathrm{E}$ layer sunset local times, $T_{S C E 1}$ and $T_{S C E 2}$, for the same period of the year. We notice that the maximum occurrence rate, which reaches $80 \%$, is confined to $2200-0100$ LT range throughout this period. During these local time intervals, plasma bubbles occur on more than $50 \%$ of the nights from approximately the middle of October to the middle of February. From a comparison of Figures 2 and $4 \mathrm{a}$ it is clear that this period also coincides with low values of local time difference $\left(T_{S C E 1}-T_{S C E 2}=\Delta T_{S C E}\right)$ between the sunsets at the conjugate $\mathrm{E}$ layers. The low values of $\triangle T_{S C E}$ generally favor large prereversal evening $F$ region drift enhancement and hence the occurrence of the plasma bubble/spread $\mathbf{F}$ irregularities. We might therefore expect that very small (or zero) $\triangle T_{S C E}$ values, corresponding to the nodal points in Figure 4d, could produce still larger drift velocity and hence maxima in the spread $F$ occurrence probability at those points. However, we notice the existence of reduced probabilities, in the form of two secondary minima (indicated by vertical lines), one in the later half of November and the other one during the changeover from January to February, at or close to the nodal points. This close coincidence of the spread F occurrence min- 

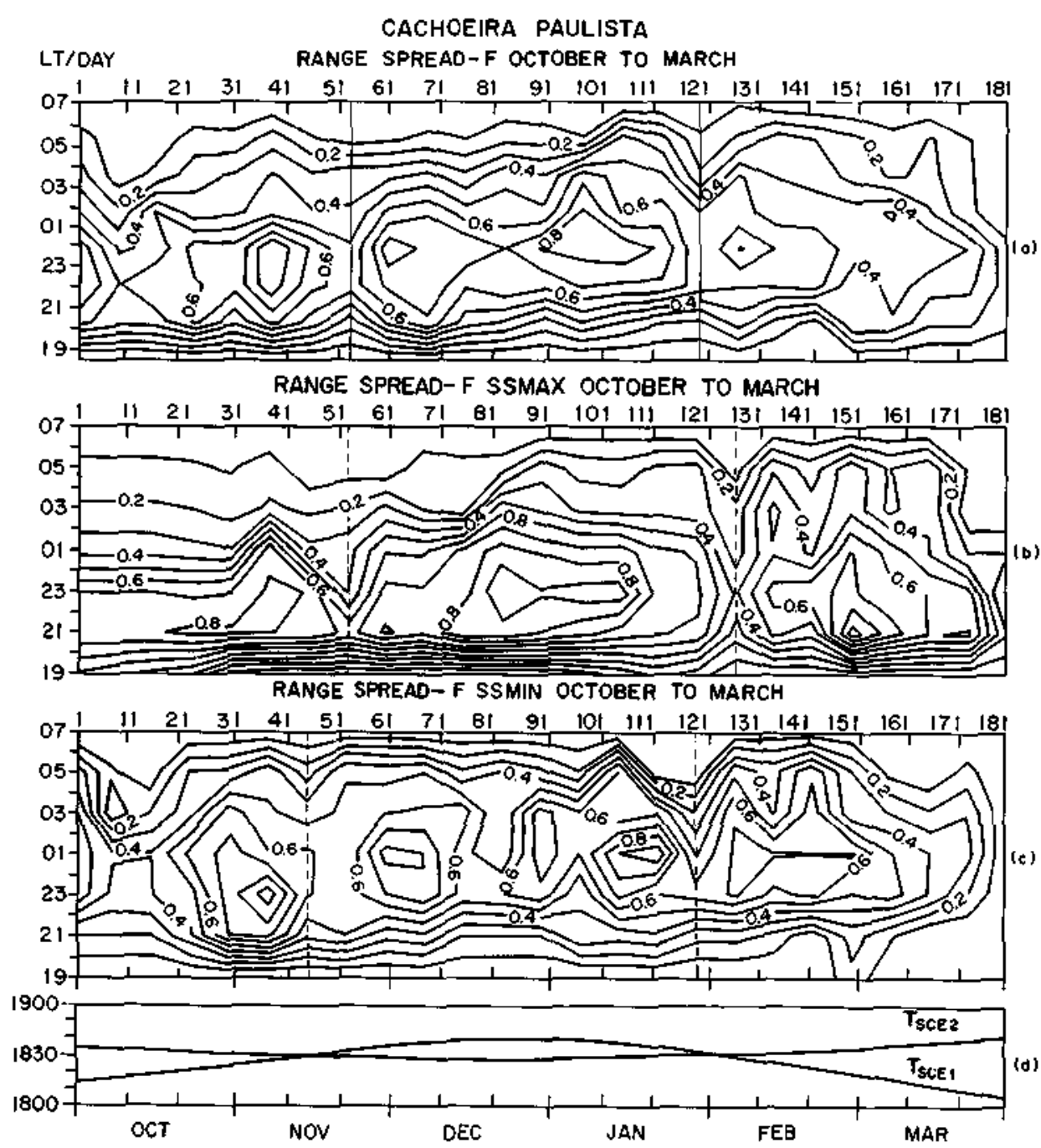

Fig. 4. (a) RSF distribution during its main occurrence season from October to March over Cachoeira Paulista, for the 12-year period 1978-1990; the grid points are separated by 1 day along the abscissa and $15 \mathrm{~min}$ along the ordinate; (b) RSF distribution statistics similar to those of Figure 4 a but representing only the years 1978-1982 and 1988-1990 for solar maximum conditions (marked as SSMAX in the figure); (c) plots similar to Figure 4b for the years 1983-1987 representing solar minimum years (SSMIN); and (d) the sunset local times, $T_{S C E 1}$ and $T_{S C E 2}$, for the northern and southem magnetically conjugate E layers, respectively.

ima and the $T_{S C E}$ nodal points is a very striking phenomenon, the statistical validity of which is highlighted by the fact that 12 years of data have provided the base for this spread $F$ occurrence feature.

The results of Figure 4a, which represent an average picture for a complete solar activity cycle, were separated into two groups, one to represent an average for the years centered around the solar minimum and the other for the years centered around the solar maxirnum. The years 1983-1987 were taken to represent the former group while the years 1978-1982 and 1988-1990 represented the latter. The average range spread $\mathrm{F}$ distributions for these two cases are plotted in Figures $4 \mathrm{~b}$ and $4 \mathrm{c}$, respectively. Dashed vertical lines are drawn through the two secondary minima in the occurrence rates. In spite of the reduced data statistics for the two separate groups the secondary minima have come out very clearly for both groups. The February minimum for the solar maximum group is specially striking. Another point to note is a systematic phase difference in the occurrence of the minima for the two groups, both of the minima during the solar maximum years lagging by 7.8 days behind those for the solar minimum years. Somewhat reduced amplitudes of these minima (with some days of displacement) in the complete solar cycle averaged data of Figure $4 \mathrm{a}$ are therefore to be expected.

We may note further that the reduction in the spread $\mathbf{F}$ is observed, in varying degrees, both during the dusk to midnight hours and during the midnight to morning hours. Both types of reductions are present in the minima of Figure 4a, which represents the mean behavior for a complete solar cycle. The same is true to a striking degree in the case of the February minimum of Figure $4 \mathrm{~b}$ (which represents the mean for the solar maximum conditions) and to a smaller degree in the November minimum of Figure 4c (for the mean conditions of the solar minimum years). For the rest of the cases the spread $F$ reduction is confined either to the near-midnight hours, as in the November minimum of Figure $4 \mathrm{~b}$, or to the midnight to morning hours, as in the January minimum of Figure 4c. A possible explanation of this behavior will be attempted below. 


\section{Discussion of THE Results}

The statistical results of Figures 1 and 2 are given in terms of monthly mean spread $F$ occurrence rates (expressed in percentage of the total observational days for the month) for a 12-month period plotted as a function of local time. At the equatorial station Fortaleza the seasonal pattern is characterized by a broad maximum covering the equinoctial and summer months, September-April. Over the low-latitude station, however, the spread $\mathrm{F}$ distribution has a maximum occurrence weighted more to the summer month of December with $90 \%$ probability. At both locations we have noted a tendency for reduced spread $F$ occurrence in November and February (indicated by arrows in Figures 1 and 2). This was quite apparent in the statistics over Fortaleza and somewhat less so over Cachoeira Paulista. These two secondary minima (the primary minimum being the one centered around the winter months of June-July for our longitude [Abdu et al, 1981a]), seen in the monthly mean spread $F$ occurrence probability, are in fact the same as the ones that are evident also in the daily occurrence probability for the 12-year period presented in Figures $4 a, 4 b$ and $4 c$. Further, in spite of the reduced data statistics for the two separate groups in Figures $4 \mathrm{~b}$ and $4 \mathrm{c}$, the secondary minima have come out very clearly for both groups. Thus the present results establish the existence of two epochs (windows) of reduced spread $\mathrm{F}$ occurrence during the general period of the seasonal maximum in its activity over our station. The following aspects of the characteristics of these minima need to be pointed out further. While the reduced occurrence that contributes to the minimum in the near-midnight to morning hours could be caused by reduced duration (faster decay) of the spread $F$ events (whose onset is at dusk to midnight as a result of quiet time $F$ region dynamo action), the part of the minima that shows up at dusk to midnight arises primarily from a reduction in the spread $F$ occurrence rate itself at these hours.

The coincidence, or nearly so, of the two secondary minima with the nodal points of the conjugate $E$ layer sunset local times (that is, $\Delta T_{S C E} \simeq 0$ ) looks to be an intriguing phenomenon. However, from consideration of the plasma bubble irregularity generation based on the Rayleigh-Taylor (R-T) instability mechanism, such a result does seem to be explainable. The gravitational R-T instability growth rate factor (see, for example, $O_{s-}$ sakow et al. [1979], Zalesak et al. [1982], and Abdu et al. [1982]) for the instability development in the bottomside gradient region of the $\mathbf{F}$ layer is given by

$$
\gamma=\left(\mathbf{E} \times \mathbf{B} / B^{2}-\mathbf{U}_{\mathbf{n}}-\mathbf{g} / \nu_{i n}\right) \cdot \nabla n / n-\nu_{\mathbf{r}},
$$

which is a simplified version of that given by Zalesak et al. [1982]. Here $\nu_{i n}$ is the ion-neutral collision frequency, $\nu_{r}$ is the recombination rate, $n / \nabla n$ is the vertical gradient scale length of the electron density, $\mathbf{E}$ and $\mathbf{B}$ are the electric and magnetic fields, and $\mathbf{U}_{\mathbf{n}}$ is the zonal neutral wind taken positive westward. Here the two parameters that present significant and rather fast changes at the sunset hours are the vertical ionization drift (prereversal enhancement) $\mathbf{E} \times \mathbf{B} / B^{2}$ and the vertical component $d n / d z$ of the layer density gradient $(\nabla n)$. An explanation of the observed spread $\mathbf{F}$ feature is therefore attempted below in terms of the sunset changes in these two parameters.

As was mentioned earlier, theoretical and numerical simulation studies based on the electrodynamic processes of the equatorial ionosphere [Rishbeth, 1971; Heelis et al., 1974; Batista et al, 1986] show that the Pedersen conductivity longitudinal gradient of the conjugate $\mathrm{E}$ layers (which are linked to the equatorial $\mathrm{F}$ region) plays a major role in the determination of the onset time and amplitude of the prereversal drift enhancement at sunset hours [Batista et al., 1986]. The steeper this gradient, the higher the amplitude of $V_{z p}$. The degree of the conductivity gradient, on the other hand, would depend upon the degree of alignment of the sunset terminator with the magnetic meridian of the conjugate $\mathrm{E}$ layers in such a way that perfect alignment, which occurs in summer months over the Brazilian sector, could produce the steepest gradients. Broad seasonal maxima in $V_{z p}$ and spread $F$ occur over Brazil, therefore, in summer months, when the magnetic declination angle favors better alignment of the terminator with the magnetic meridian of the conjugate $\mathrm{E}$ layers.

The vertical drift of the layer could be associated with changes in the layer bottomside density gradient as well, in such a way that for a specific density gradient the attainment of a threshold value for the vertical drift (and the layer height) or vice versa sets the condition for the triggering of the instability processes. Two situations to be considered in this context are (1) a height independent (uniform) vertical drift that will cause vertical uplift of the layer without altering the bottomside density gradient and (2) drift varying with height that could significantly alter the density gradient. The two circumstances for the occurrences of these two types of prereversal vertical drift (eastward electric field) enhancement under the action of the $F$ region dynamo development at sunset hours are depicted in Figures 5 a and $5 \mathrm{~b}$. The representations in these figures have been based partly on a physical explanation for the prereversal evening electric field enhancement given by Farley et al. [1986]. Figeres $5 \mathrm{a}$ and $5 \mathrm{~b}$ are basically identical to each other except for the difference in the alignment of the sunset terminator (shown by the dash-dotted line) with the magnetic meridian, which is perfect in Figure $5 \mathrm{a}$ and only partial in Figure 5b. The equatorial $F$ region cross section in the vertical east-west plane is linked to magnetically conjugate $\mathrm{E}$ layers in the horizontal plane as depicted in these figures. A zonal $\mathbf{F}$ region wind $\mathbf{U}$ blowing eastward across the terminator (near sunset) produces a downward electric field $E_{z}$ (whose value is a significant fraction of $\mathbf{U} \times \mathbf{B}$ ) which maps along the geomagnetic field lines to an equatorward meridional field, $E_{\theta}$ (not shown explicitly), in the conjugate E layers. As explained by Farley et al. [1986], a westward electric current that is to be driven by $E_{\theta}$ is stopped from flowing because of the day to night discontinuity (rather, westward gradient) in the Hall conductivity. The resulting buildup of polarization charges (shown by negative signs) at the terminator leads to an eastward zonal field on the dayside and a westward field on the nightside. In Figure $5 \mathrm{a}$ where we have considered a perfect alignment of the terminator with the magnetic meridian, an ideal situation of latitudinally uniform polarization charge is likely to exist which by field 
(0)
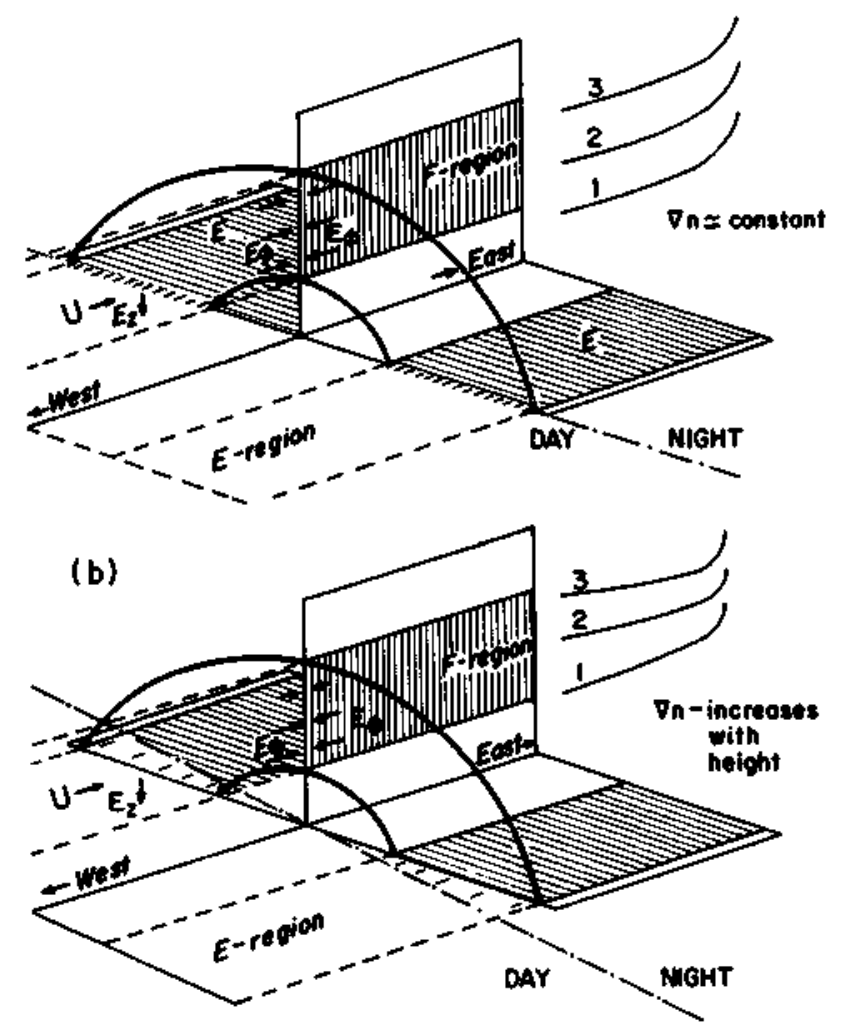

Fig. 5. Schematic representation of the $F$ layer dynamoinduced prereversal enhancement in the zonal electric field near sunset hours. Magnetic field lines couple the equatorial $F$ layer (shown in east-west vertical plane) with the $E$ layer in the horizontal plane. The $F$ region eastward neutral wind $U$ in the vertical plane produces downward $\mathbf{E}_{\mathbf{z}}=-\mathbf{U} \times \mathbf{B}$. This field maps to an equatorward $\mathbf{E}_{\theta}$ (not shown explicitly) in the $E$ layer that tends to drive a westward Hall current which is prevented from flowing since no current flows in the nightside $\mathrm{E}$ region. The resulting buildup of negative charges is shown by negative signs near the terminator, and the resulting zonal electric field maps back to the $F$ region. (a) A latitudinally uniform distribution of negative polarization charges, corresponding to terminator alignment with the magnetic meridian, gives rise to eastward and westward electric field $\left(E_{\phi}\right)$ shown height independent in the vertical plane. (b) The case of the terminator making an angle with the magnetic meridian, producing a height gradient in the zonal electric field.

line mapping produces a height independent uniform zonal electric field (shown as $E_{\phi}$ in the figure) within the height region under consideration. Consequently, the $\mathrm{F}$ layer bottomside electron density distribution is expected to remain unaltered (that is, $\nabla n \simeq$ const, as depicted in profiles 1,2 , and 3 of this figure) as the $F$ layer is lifted up under the action of the eastward zonal electric field.

In Figure $5 \mathrm{~b}$ we have introduced an angle between the sunset terminator and the magnetic meridian so that the $\mathrm{E}$ layer on the nightside of the terminator makes magnetic conjugacy with the $E$ layer on the dayside. Further, the separation of the terminator from the pair of magnetically conjugate $\mathrm{E}$ layers could increase going away from the equator in both hemispheres, as shown in the figure. This could result, from field line mapping, in a decrease with latitude in the polarization charge with increasing distance from the equator. The degree of the decrease, and therefore that of the height gradient in the zonal electric field (shown as $E_{\phi}$ in the figure, in the vertical F layer plane), would, of course, depend upon the angle between the terminator and the magnetic meridian. For small angles the height gradient should also be small. As a result of the height dependent zonal electric field (that is, vertical drift) the uplift of the $F$ layer occurs with the electron density vertical gradient, $\nabla n$, increasing with altitude, as the electron density profiles at the three positions (identified as 1 , 2 , and 3 in the figure) are made to depict.

In the expression for the instability growth rate mentioned before, the two parameters that undergo rapid changes at the sunset are $\mathbf{E} \times \mathbf{B} / B^{2}$ and $\nabla n / n$, and two types of development in these two parameters were considered above that corresponded to the two situations of terminator alignment with the magnetic meridian. It is possible that in the situation in Figure 5a, that is, at the nodal points representing a perfect alignment of the terminator with the magnetic meridian, the bottomside $F$ region, where $\nabla n$ is considered invariant with the uplift of the layer, could be subjected to a regime that is less unstable as compared to the situation in Figure $5 b$, that is, in the region away from the nodal points, where the required steepening of the electron density gradient occurred with the layer uplift. The secondary minima seen in Figures 1, 2, 4a, 4b, and $4 c$ do seem to fit in with the picture of the $F$ layer dynamo electric field development, which includes the north-south asymmetry, as described above. A more detailed and quantitative evaluation of the observed spread $F$ seasonal feature is in progress.

An effect similar to that observed in our data should be present in other longitude sectors as well. However, their identification will require a treatment of the data statistics with sufficient temporal resolution. Our consideration of daily values for the 12-year period has brought out the effect better (in Figure 4) than when we considered the monthly mean values for a given year (Figures 1 and 2). Suggestion of a similar effect is seen also in some cases of a global scintillation data set analyzed by Tsunoda [1985]. For example, in his Figure $2 \mathrm{~d}$ for Kwajalein, the seasonal distribution presented with 15-day values from livingstone [1980] appears to be a striking example of this effect. Very close to the two nodal points there are clear minima. Most of the rest of the characteristics of this figure also resemble the spread $\mathrm{F}$ distribution pattern of our Figure 4 . Of course, it should be pointed out that a perfect coincidence of the secondary minima with the nodal points does not necessarily have to happen since the coexisting vertical drift and $\nabla n$ evolutions that we consider may not take place strictly as depicted in Figures $5 \mathrm{a}$ and $5 \mathrm{~b}$. For example, the possible existence of a latitude dependent zonal wind and conductivity distribution could shift the occurrence of latitudinally (and heightwise) uniform zonal electric field, supposed to be coinciding with the nodal points, to regions somewhat away from them. Such a situation is probably responsible for the shift of the secondary minima with respect to the nodal points seen in the results of Figures $4 \mathrm{~b}$ and $4 \mathrm{c}$. In particular, the sys- 
tematic shift (that is, the delay by 7 to 8 days) of these minima during solar maximum (Figure $4 \mathrm{~b}$ ) compared to those of the solar minimum (Figure $4 \mathrm{c}$ ) would seem to imply a corresponding solar cycle effect on the annual thermospheric neutral wind pattern.

We should point out further that the relatively less unstable bottomside $\mathbf{F}$ region situation described above (based on Figure 5a) could result (1) in reduced occurrence and/or (2) in the occurrence of weak and therefore shorter-duration events. Both of these possibilities are borne out by the occurrence of the minima during the dusk to midnight hours and during the postmidnight (extending to dusk) hours, respectively, seen in varying degrees in the different statistical groupings of the data presented in Figures $4 a, 4 b$ and $4 c$. The spread $F$ duration is known to be sensitive to $F$ region heights [Nelson et al, 1986] and its variation and chemical loss times at these heights [Somayajulu et al., 1975]. The decrease in the spread $F$ duration associated with the nodal points, which is of concern in item 2 above, implies control of this duration by the $F$ region bottomside density gradients as well.

\section{CONCLUSIONS}

The analysis of range spread $F$ data over Brazilian stations Fortaleza and Cachoeira Paulista carried out in the present work confirms the earlier findings that the magnetic declination angle does control the gross seasonal pattern of the evening $F$ region dynamo electric field development and associated spread $\mathrm{F}$ plasma bubble development. However, on the basis of the previous findings and conclusions regarding attaining a threshold height [Farley et al., 1970] or a velocity [Abdu et al., $1983 \mathrm{~b}$ ] as a requirement for the spread $F$ development one would expect an almost exactly identical seasonal variation in the vertical drift and RSF occurrences. The departure in their behavior, in view of the fine structure of the RSF seasonal pattern observed here, does seem to point to new factors to be considered in our understanding of the irregularity generation mechanism.

The following are the main conclusions from the present study:

1. Small angles between the sunset terminator and magnetic meridian favor postsunset spread $F$ development.

2. Perfect (or nearly so) alignment of the terminator with the magnetic meridian, the condition of conjugate $E$ layer sunset nodal points, however, tends to decrease the efficiency for the irregularity growth, thereby producing secondary minima in their occurrences at the nodal points.

3. A simple physical interpretation of the observed phenomenon shows that both the $\mathrm{F}$ region vertical drift (zonal electric field) and its height gradient need to be considered in determining the spread F onset conditions. It appears that the steepening of the bottomside density gradient could be produced by a height gradient in eastward electric field.

These results do seem to have important implications for the amplitude of an initial perturbation required to trigger development of a plasma bubble irregularity.
A cknowledgments. This work was partially supported by FNDCT under contract FINEP 537/CT. The authors have been partially supported by the Conselho Nacional de Desenvolvimento Científico e Tecnológico under processes 300509/89.8, 500003/91.2, and 501771/91.3. Our thanks to Lúcia de Almejda Terra Limiro, who was responsible for the reducing of jonogram spread $\mathbf{F}$ data.

The editor thanks S. Basu, D. T. Farley, and R. G. Rastogi for their assistance in evaluating this paper.

\section{REFERENCES}

Abdu, M. A., I. S. Batista, and J. A. Bittencourt, Some characteristics of spread $F$ at the magnetic equatorial station Fortaleza, J. Geophys. Res., 86, 6836-6841, 1981 a.

Abdu, M. A., J. A. Bittencourt, and I. S. Batista, Magnetic declination control of the equatorial $F$ region dynamo electric field development and spread F, J. Geophys. Res., 86, 11443-11446, $1981 \mathrm{~b}$.

Abdu, M. A., R. T. de Medeiros, and J. H. A. Sobral, Equatorial spread-F instability conditions as determined from jonograms, Geophys. Res. Lett., 9, 692$695,1982$.

Abdu, M. A., R. T. de Medeiros, J. H. A. Sobral, and J. A. Bittencourt, Spread $\mathbf{F}$ plasma bubble vertical rise velocities determined from spaced ionosonde observations, J. Geophys. Res., 88, 9179-9204, $1983 \mathrm{a}$.

Abdu, M. A., R. T. de Medeiros, J. A. Bittencourt, and I. $\mathrm{S}$. Batista, Vertical ionization drift velocities and range type spread $F$ in the evening equatorial ionosphere, $J$. Geophys. Res., 88, 399-402, 1983b.

Abdu, M. A., P. Muralikrishna, I. S. Batista, and J. H. A. Sobral, Rocket observations of equatorial plasma bubbles over Natal, Brazil, using a high-frequency capacjtance probe, J. Geophys. Res., 96, 7689-7695, 1991.

Basu, S., and S. Basu, Equatorial scintillatjon - A revjew, J. Atmos. Terr. Phys., 43, 473-489, 1981.

Batista, I. S., M. A. Abdu, and J. A. Bittencourt, Equatorial $F$ region vertical plasma drift: Seasonal and longitudinal asymmetries in the American sector, $J$. Geophys. Res., 91, 12055-12064, 1986.

Chandra, H., and R. G. Rastogi, Equatorial spread $F$ over a solar cycle, $A n n$. Geophys., 28, 709-715, 1972.

DasGupta, A., J. Aarons, J. A. Klobuchar, S. Basu, and A. Bushby, Ionospheric electron content depletions associated with amplitude scintillations in the equatorial region, Geophys. Res. Lett., 9, 147-150, 1982.

Farley, D. T., B. B. Balsley, R. F. Woodman, and J. P. McClure, Equatorial spread F: Implications of VHF radar observations, J. Geophys. Res., 75, 7199-7210, 1970 .

Farley, D. T., E. Bonelli, B. G. Fejer, and M. F. Larsen, The prereversal enhancement of the zonal electric field in the equatorial ionosphere, J. Geophys. Res., 91, 13723-13728, 1986 .

Fejer, B. G., D. T. Farley, R. F. Woodman, and C. Calderon, Dependence of equatorial $F$ region vertical drifts on season and solar cycle, J. Geophys. Res., 84, 5792-5796, 1979.

Haerendel, G., Theory of equatorial spread F, report, Max Planck Inst. für Phys. und Astrophys., Munich, Germany, 1973.

Hanson, W. B., and D. W. Bamgboye, The measured motion inside equatorial plasma bubbles, $J$. Geophys. Res., 89, 8997-9008, 1984 .

Hanson, H. B., and S. Sanatani, Large Ni gradient below the equatorial $\mathrm{F}_{2}$ peak, $J$. Geophys. Res., $78,1167-$ $1173,1973$.

Heelis, R. A., P. C. Kendall, R. J. Moffet, D. W. Win. dle, and $H$. Rishbeth, Electrical coupling of the $E$ and $F$ regions and its effect on $F$ region drifts and winds, Planet. Space Sci., 22, 743-756, 1974.

Huang, Y. N., K. Cheng, and W. T. Huang, Seasonal and solar cycle variations of spread-F at the equatorial anomaly crest, J. Geomagn. Geoelectr., $39,639 \cdot 657$, 1987. 
Kelley, M. C., G. Haerendel, H. Kappler, A. Valenzuela, B. B. Balsley, D. A. Carter, W. L. Ecklund, C. W. Carlson, B. Hausler, and R. Torbert, Evidence for a RayleighTaylor type instability and upwelling of depleted density regions during equatorial spread F, Geophys. Res. Lett., $s, 448-450,1976$.

Livingstone, R. C., Comparison of multifrequency equatorial scintillation: American and Pacific sectors, Radio Sci., $15,801+804,1980$.

McClure, J. P., W. B. Hanson, and J. F. Hoffman, Plasma bubble and irregularities in the equatorial ionosphere, J. Geophys. Res., 82, 2650-2656, 1977.

Mendillo, M., and J. Baumgardner, Airglow characteristics of equatorial plasma depletions, J. Geophys. Res., $87,7641.7652,1982$.

Nelson, O. R., M. A. Abdu, and I. S. Batista, Equatorial $F$ region irregularity extension and dynamo electric field, J. Atmos. Terr. Phys., \&8, 181-186, 1986 .

Ossakow, S. L., S. T. Zalesak, B. E. McDonald, and P. K. Chaturvedi, Nonlinear equatorial spread F: Dependence on altitude of the peak and bottomside electron density gradient scale length, $J$. Geophys. Res., 84, $17.29,1979$

Rastogi, R. G., Seasonal and solar cycle variation of equatorial spread $\mathrm{F}$ in the American zone, J. Atmos. Terr. Phys., 47, 593-597, 1980 .

Rastogi, R. G., Tropical spread F, Indian J. Radio Space Phys., 12, 104-113, 1983.

Rastogi, R. G., HF jonosonde and VHF backscatter observations of equatorial spread F, Ann. Geophys., \$, 581-588, 1985 .

Rishbeth, H., Polarization fields produced by winds in the equatorial F region, Planet. Space Sci., 19, 357-369, 1971.

Sobral, J. H. A., and M. A. Abdu, Latitudinal gradient in the plasma bubble zonal velocities as observed by scanning $630-\mathrm{nm}$ airglow measurements, $J$. Geophys. Res., 95, 8253-8257, 1990.

Sobral, J. H. A., M. A. Abdu, I. S. Batista, and C. J. Zamlutti, Association between plasma bubble irregularities and airglow disturbances over Brazilian low latitude, Geophys. Res, Lett., 7, 980-982, 1980.
Somayajulu, V. V., K. Sen Gupta, and B. V. Krishna Murty, Duration of equatorial spread F, Nature, 257, 112-113, 1975.

Tsunoda, R. T., Time evolution and dynamics of equatorial backscatter plumes, 1, Growth phase, J. Geophys. Res., 86, 139-149, 1981.

Tsunoda, R. T., Control of the seasonal and latitudinal occurrence of equatorial scintillation by the longitudinal gradient in the integrated $E$ region Pedersen conductivity, J. Geophys. Res., 90, 447-456, 1985.

Tsunoda, R. T., R. C. Livingstone, J. P. McClure, and W. B. Hanson, Equatorial plasma bubbles: Vertically elongated wedges from the bottomside layer, J. Geo. phys. Res., 87, 9171-9180, 1982.

Weber, E. J., J. Buchau, and J. G. Moore, Ajrborne studies of equatorial $\mathrm{F}$ layer ionospheric irregularities, $J$. Geophys. Res., 85, 4631-4641, 1980.

Woodman, R. F., Vertical drift velocities and east-west electric fields at the magnetic equator, J. Geophys. Res., 75, 6249-6259, 1970.

Woodman, R. F., and C. La Hoz, Radar observations of F region equatorial irregularities, $J$. Geophys. Res., 81 , $5447-5466,1976$.

Yeh, K. C., J. P. Mullen, J. R. de Medeiros, R. F. da Silva, and $R$. T. de Medeiros, Ionospheric scintillation observations at Natal, J. Geophys. Res., 86, 7527.7532, 1981 .

Zalesak, S. T., S. L. Ossakow, and P. K. Chaturvedi, Nonlinear equatorial spread $F$ : The effect of neutral winds and background Pedersen conductivity, J. Geophys. Res., 87, 151-166, 1982.

M. A. Abdu, I. S. Batista, and J. H. A. Sobral, Aeronomy Division, INPE, Avenida dos Astronautas, 1758, Cajxa Postal 515, 12201, São José dos Campos, São Paulo, Brazil.
(Received October 15, 1991 . revised March 30, 1992; accepted April 1, 1992.) 